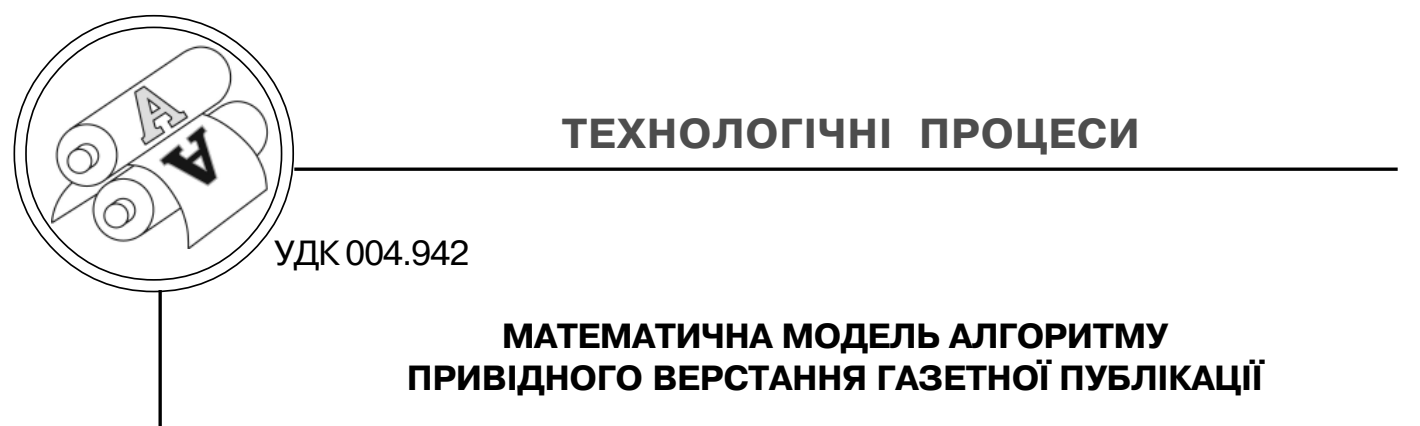

( В. М. Сеньківський, д.т.н., професор,

І. В. Гілета, ст. викладач, УАД, Львів, Україна

\begin{abstract}
Обоснована целесообразность автоматизации верстки газетного издания. Определены способы приводной верстки публикации газетной полосы, способ и порядок их применения.
\end{abstract}

The necessity of automation layout of newspaper edition is proved. Determine the means conciliation newspaper page layout publications, as the manner and sequence of their application.

\section{Постановка проблеми}

Верстання сторінок є одним із найбільш важливих, складних та відповідальних етапів комп' ютеризованої технології випуску газетних видань. В основі верстки газетної шпальти лежить макетна сітка. Створений за її допомогою макетний бланк відтворює газетну шпальту. Він дає чітке уявлення про розподіл матеріалів на шпальті та всі деталі оформлення. Основою для створення макета є план номера. Макет повинен забезпечити швидке і чітке верстання шпальт видання згідно з графіком випуску номера.

Головним принципом пропорціонування при розміщенні матеріалів на шпальті $€$ використання модульної сітки. Вона задає єдність і цілісність конструкції оформлення і загалом визначає організацію текстового та ілюстративного матеріалу на шпальті. Вертикальні лінії сітки визначають внутрішні і зовнішні поля, ширину колонки, міжколонний інтервал. Горизонтальні лінії сітки задають верхні і нижні поля, висоту колонок, розміщення ілюстративного матеріалу та заголовків. Модульна сітка $€$ набором напрямних ліній вздовж яких розміщується матеріал газетної сторінки. Горизонтальні та вертикальні напрямні модульної сітки визначають прямокутні блоки. Відношення між висотою та шириною цих блоків близьке до значення пропорції золотого перетину [2].

Складовими елементами макета газети $€$ текстові та ілюстративні блоки, які прийнято називати матеріалами публікації шпальти. Зрозуміло, що ілюстрація як окрема публікація може мати у своєму складі текстовий підпис; публікація текстовий блок потенційно складається 3 цілої групи окремих елементів: основного тексту, заголовку, однієї або декількох ілюстрацій 
та інших пояснювальних компонент. Розмір окремого блоку визначається обсягом та параметрами матеріалу, а форма i розміщення задається вагою його вмісту та взаємодією 3 іншими матеріалами на шпальті. Проектування макета газетної шпальти передбачає планування розміщення блоків публікацій на площі сторінки.

Використання комп'ютерних видавничих систем кардинально змінило суть процесу додрукарського підготування видань: він став більш стилізованим, побудованим на основі використання готових шаблонів конкретної системи. Попереднє підготування шаблонсторінок певним чином автоматизує процес верстання, однак по суті він залишається діалоговим і його результат значною мірою залежить від кваліфікації верстальника. 3 одного боку - це професійні якості, тобто вміння оперувати можливостями програмного пакету; володіння поліграфічними основами формування видань; знання правил компонування сторінок, що містять різні елементи складності. Це, так би мовити, формальна сторона справи, яку можна вивчити і досить грамотно використовувати. 3 другого боку - творчий, неформальний характер верстання і художній рівень результату цього процесу. Таким чином, особисті якості верстальника, його здатність до прийняття неординарних рішень є визначальними для оцінки естетичного рівня друкованої продукції. Тому доцільною є потреба в ефективних алгоритмах та програмах автоматичного верстання, які могли б забезпечити належну якість і, що досить суттєво, значно скоротити час бепосередньої роботи верстальника за комп'ютером, звести до мінімуму суб'єктивні фактори.

У свій час подібні системи для верстання книг були розроблені в Українському НДІ поліграфічної промисловості ім. Т. Шевченка та успішно використовувалися поліграфічними підприємствами України, Росії, Молдови.

Орієнтація на автоматичне верстання додатково вимагає врахування таких характеристик, як величини пробілів між словами та проміжків між літерами, рівномірність їх значень в межах абзацу, якість переносів, суть та кількість порушень при верстанні різних елементів текстової публікації. Також часто використовується зміна гарнітури основного шрифту та розміщення публікації у нестандартній кількості колонок. Зазначені засоби дають можливість керувати величиною площі, яку займе публікація в макеті. Для надання потрібних розмірів вмісту текстового блоку визначимо алгоритм привідного верстання, який забезпечить вибір засобів та способів його застосування для зміни параметрів газетної публікації.

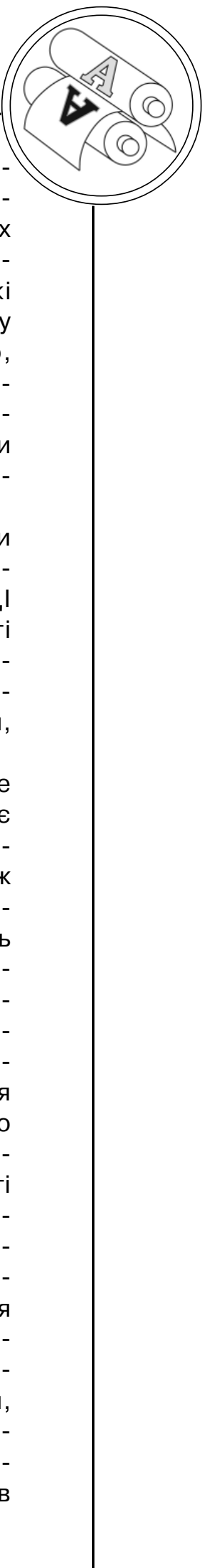




\section{ТЕХНОЛОГІЧНІ ПРОЦЕСИ}

\section{Мета роботи}

Введемо позначення: нехай $\mathrm{S}_{1}$ - площа газетної полоси, H - висота полоси набору, L - ширина полоси набору. Загальна площа набору обчислюється добутком $\mathrm{S}_{1}=\mathrm{H} \cdot \mathrm{L}$. Якщо: $S_{2}$ - сукупна площа матеріалів, $S_{1}$ - площа і-ої окремої публікації, тоді справедлива рівність:

$$
\mathrm{S}_{2}=\sum_{\mathrm{i}=1}^{\mathrm{n}} \mathrm{S}_{\mathrm{i}}
$$

де $\mathrm{n}$ - кількість публікацій.

Алгоритм привідного верстання окремих публікацій газетної шпальти повинен забезпечити виконання умови $\Delta S>0$, яка визначається 3 формули

$$
\Delta \mathrm{S}=\mathrm{S}_{1}-\mathrm{S}_{2}=\left[(\mathrm{L} \times \mathrm{H})-\sum_{\mathrm{i}=1}^{\mathrm{n}} \mathrm{S}_{\mathrm{i}}\right] \cdot(1)
$$

Створення оптимального алгоритму, який одночасно враховував би всі обмеження та вимоги, є досить складною, а може й взагалі нерозв'язною задачею з огляду на множину всіх показників, які характеризують якість готових сторінок та практично необмежений асортимент структурних схем сторінок і варіантів взаємного розміщення в них різних елементів. Тому перспективним видається метод введення та використання вагових коефіцієнтів пріоритетності виконання поліграфічних вимог, які стосуються правил верстання газетної сторінки. Метод дозволяе приймати обґрунтовані рішення в тих випадках, коли не вдається уникнути порушень, фактично корелюючи функцію якості видання. При цьому ймовірність додаткового втручання оператора-верстальника в процес верстання стає мінімальною.

\section{Модель алгоритму}

привідного верстання

Загальний розмір матеріалу публікації обчислимо як суму розмірів його складових частин: текстового матеріалу публікації, ілюстрацій, заголовка, пояснюючих елементів та відбивки. Обрахунок здійснюється за кількістю рядків основного тексту [1].

щоб порахувати кількість рядків, яку займе основний текст в матеріалі публікації скористаємось наступними міркуваннями. Загальна кількість символів публікації відома. Сумарна кількість рядків основного тексту визначається співвідношенням

$$
\mathrm{Kr}_{\mathrm{t}}=\frac{\mathrm{O}}{\mathrm{Kz}} \text {, }
$$

де О - загальний обсяг тексту, $\mathrm{Kz}$ - кількість знаків в рядку колонки.

Кількість рядків основного тексту, яку займе заголовок, визначається рівністю

$$
\mathrm{Kr}_{\mathrm{z}}=\mathrm{n} \times\left(\frac{\mathrm{Kg}_{\mathrm{z}}}{\mathrm{Kg}_{\mathrm{t}}}+\mathrm{Kg}_{\mathrm{t}}+\mathrm{v}\right)
$$

де $\mathrm{n}$ - кількість рядків заголовка, $\mathrm{Kg}_{\mathrm{z}}$ - величина кеглю шрифту заголовка, $\mathrm{Kg}_{\mathrm{t}}$ - величина кеглю шрифту тексту, v - відбивка заголовку від тексту (як правило, для газет 3-4 пункти).

Обчислення кількості рядків тексту, яку займуть ілюстрації в текстовій публікації здійснюємо, 
наступним чином. Спочатку визначаємо необхідну висоту ілюстрацій виміряну у долях квадрата:

$$
\mathrm{h}_{\mathrm{i}}^{\prime}=\left(\mathrm{h}_{\mathrm{i}} / \mathrm{l}_{\mathrm{i}}\right) \mathrm{l}_{\mathrm{i}}^{\prime},
$$

де $\mathrm{h}_{\mathrm{i}}$ - висота $i$-ої ілюстрації, $\mathrm{I}_{\mathrm{i}}$ ширина і-ої ілюстрації, l' - ширина ілюстрації на задану кількість квадратів. Далі визначаємо необхідну кількість рядків основного тексту

$$
\mathrm{Kr}_{\mathrm{i}}=\frac{\mathrm{h}}{\mathrm{Kg}_{\mathrm{t}}+\mathrm{in}},
$$

де $\mathrm{h}$ - висота публікації виміряна в квадратах, in - інтерліньяж основного тексту.

Визначимо параметри публікації, які забезпечать можливість розміщення вмісту блоку в задане місце. У загальному випадку розгляд процесу приведення вмісту визначається кількістю рядків тесту, яких бракує чи, навпаки, є надлишок у текстовому блоці. Тому оцінка ситуації для наступних дій полягає у визначенні режиму вгонки-вигонки рядків тексту. При надлишку рядків потрібна вгонка визначеної кількості рядків, а при недостатній кількості - вигонка.

Послідовність реалізації варіантів приведення публікації до заданих розмірів визначається відсотком рядків, для яких передбачається операція вгонкивигонки. Пропонується наступна послідовність застосування засобів приведення вмісту блоку до заданого розміру:

1) зміна кількості колонок публікації;

2) зміна основного шрифту тексту;
3) зміна відступів;

4) зміна інтерліньяжу основного тексту (допускається до $10 \%)$;

5) зміна між символьного інтервалу (допускається до 3 \%).

У процедурах, що передують верстанню, більшість програмних пакетів комп'ютерних видавничих систем розраховані на попереднє утворення блоків, які служать аргументом функції верстання. Їх поділено на нетекстові і текстові. До нетекстових блоків віднесено, наприклад, рисунок, ілюстрацію, графік. Кожний з них має свої атрибути, згідно з якими приймається рішення про місце розміщення такого блоку в межах текстового блоку.

В KBC (наприклад, Adobe InDesign) основною структурною одиницею $€$ абзац, для якого задаються такі атрибути форматування, як вирівнювання тексту по горизонталі, «висячий» рядок, інтерліньяж, відбивки до і після абзацу, гарнітура, кегель, накреслення, міжсимвольний (кернінг, трекінг) та інтервали між словами. Така система задання параметрів абзацу, як аналогу своєрідного текстового блоку, досить складна, хоч і має свої переваги, що проявляються саме в процесі верстання. У підписах до ілюстрації мінімально достатнім текстовим блоком може бути рядок.

Зміна вертикальних відступів публікації

Наступні зауваження будуть стосуватися вертикальних пробільних елементів, тобто проміжків між видимими елементами публікації. До них належать: 


\section{ТЕХНОЛОГІЧНІ ПРОЦЕСИ}

інтерліньяж; відбивки до і (або) після заголовка, підзаголовка та інших пояснюючих елементів; проміжки між текстом і рисунками, ілюстраціями, графіками, таблицями, формулами. В кожному з цих випадків проміжок має певні межі задання, що змінюються від мінімального до максимального значення. Позначимо їх через $\mathrm{t}_{\mathrm{ij} \text { min }} \mathrm{i} \mathrm{t}_{\mathrm{ij}_{\max }}$, де $\mathrm{i}-$ вказує кількість типів проміжків, j - кількість проміжків даного типу. Введемо поняття зони форматування, яку визначимо, як вільний простір в кінці публікації, при досягненні якої черговим блоком публікація може вважатися завершеною. Розрахунок зони форматування публікації набраної на декілька колонок аналогічний одноколонковій. У цьому випадку фактичне вирівнювання буде здійснюватись по декількох колонках. Отже, зона форматування публікації може бути порахована за допомогою наступного виразу:

$$
\begin{gathered}
\mathrm{Z}=\sum_{\mathrm{i}=1}^{\mathrm{n}} \sum_{\mathrm{j}=1}^{\mathrm{m}}\left(\mathrm{t}_{\mathrm{ij} \mathrm{j}_{\max }}-\mathrm{t}_{\mathrm{ij} \mathrm{j}_{\min }}\right)= \\
=\sum_{\mathrm{i}=1}^{\mathrm{n}} \sum_{\mathrm{j}=1}^{\mathrm{m}} \Delta \mathrm{t}_{\mathrm{ij}} .
\end{gathered}
$$

Величина зони форматування залежить від значень мінімальної та максимальної меж величин проміжків та їх кількості в публікації, тому не може бути постійною для всіх публікацій.

Для подальшого викладу введемо позначення: $\mathrm{H}, \mathrm{H}_{1}, \mathrm{H}_{2}-$ відповідно вертикальний формат публікації та його мінімальна і максимальна допустимі межі, які вираховуються наступним чином: $\mathrm{H}_{1}=\mathrm{H}-\mathrm{Z} ; \mathrm{H}_{2}=\mathrm{H}+\mathrm{Z}$.

Це означає, що публікація, яка формується, може мати внутрішню і зовнішню зони форматування, рівні між собою. Досягнення k-м блоком меж внутрішньої зони при $\mathrm{t}_{\mathrm{ij}_{\min }}$ аналогічне входженню k + 1 блоку в зовнішню зону при $\mathrm{t}_{\mathrm{ij}_{\max }}$. В обох випадках накопичення вертикальних розмірів блоків формально завершується і за рахунок збільшення або зменшення величини проміжків між блоками публікації доводиться до заданого формату (рис. 1).

Математична модель цього процесу може бути подана наступними викладками. Основою алгоритму верстання є покрокове накопичення вертикального формату публікації додаванням вертикальних розмірів окремих блоків. Розглянемо окремо варіанти, коли межа проміжків $€$ мінімальною, або максимальною [3].

У першому випадку після кожного кроку поточний формат публікації (тобто його значення, одержане додаванням до попередньої величини вертикального розміру чергового блоку) порівнюється із $\mathrm{H}_{1}$, тобто перевіряється умова

$$
\sum_{\mathrm{r}=1}^{\mathrm{k}} \mathrm{h}_{\mathrm{r}}+\sum_{\mathrm{i}=1}^{\mathrm{n}} \sum_{\mathrm{j}=1}^{\mathrm{m}} \mathrm{t}_{\mathrm{ij}_{\min }} \leq \mathrm{H}_{1},
$$

де $\mathrm{h}_{\mathrm{y}}$ - висота $\mathrm{r}$ - го блоку; k - кількість блоків, що помістилися у публікації.

Доки поточний формат не перевищить значення $H_{1}$, процес накопичення блоків про- 


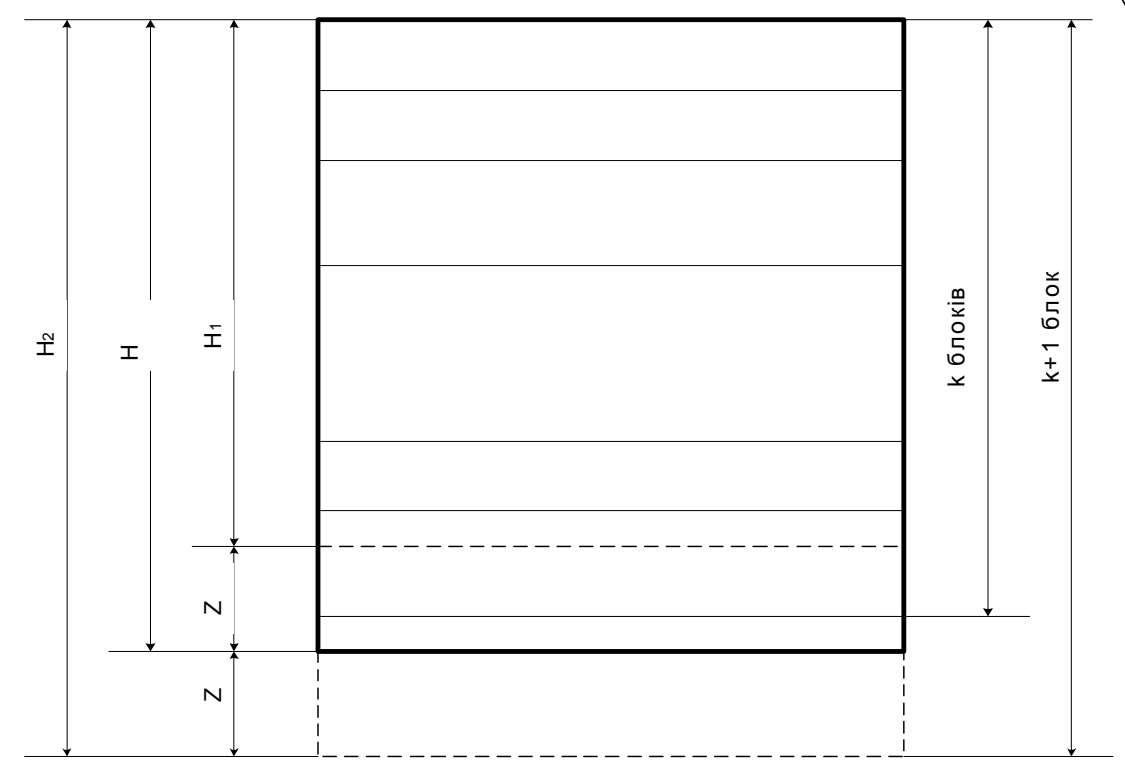

Рис. 1. Структурна схема сторінки із зоною форматування

довжується, інакше перевіряється справедливість наступного співвідношення:

$$
\mathrm{H}_{1} \leq \sum_{\mathrm{r}=1}^{\mathrm{k}} \mathrm{h}_{\mathrm{r}}+\sum_{\mathrm{i}=1}^{\mathrm{n}} \sum_{\mathrm{j}=1}^{\mathrm{m}} \mathrm{t}_{\mathrm{ij}} \leq \mathrm{H}
$$

Якщо умова (7) справджується, то накопичення блоків припиняється, хоч публікація не вважається завершеною, про що буде сказано нижче. У випадку, коли останній блок виходить за межі заданого формату, він переноситься на наступну колонку при її наявності, а на поточній необхідно перейти на діалоговий (автоматизований) спосіб завершення процесу верстання матеріалу публікації.

Аналогічні дії, застосовані до максимальних проміжків між елементами публікації, приводять до наступних співвідношень:

$$
\sum_{\mathrm{r}=1}^{\mathrm{k}+1} \mathrm{~h}_{\mathrm{r}}+\sum_{\mathrm{i}=1}^{\mathrm{n}} \sum_{\mathrm{j}=1}^{\mathrm{m}} \mathrm{t}_{\mathrm{ij} \max } \leq \mathrm{H}
$$

$$
\mathrm{H} \leq \sum_{\mathrm{r}=1}^{\mathrm{k}+1} \mathrm{~h}_{\mathrm{r}}+\sum_{\mathrm{i}=1}^{\mathrm{n}} \sum_{\mathrm{j}=1}^{\mathrm{m}} \mathrm{t}_{\mathrm{ij} \max } \leq \mathrm{H}_{2} \cdot(9)
$$

Останній блок, який не поміщається в межах зовнішньої зони форматування, автоматично переноситься на наступну сторінку.

Вирази (7) і (9) свідчать про те, що останній блок публікаціії знаходиться відповідно в межах внутрішньої, або зовнішньої зон форматування. При цьому, як було сказано вище, процес накопичення блоків припиняється. Виконання цих умов $€$, однак, лише необхідною, але недостатньою умовою завершення процесу формування сторінки. Потрібно знайти вихід в ситуації, коли праві частини виразів (7) або (9) є строгими нерівностями. В цьому випадку незаповненою залишається частина, рівна $\mathrm{H}-\mathrm{H}_{1}$ для (4) $\mathrm{i}_{2}-\mathrm{H}$ для (9), 


\section{ТЕХНОЛОГІЧНІ ПРОЦЕСИ}

тобто, відповідно, внутрішня та зовнішня зони форматування.

Знайдемо величини залишків, що припадають на кожний із типів проміжків, а саме обчислимо їх для мінімального та максимального значень проміжків між елементами публікації:

$\Delta \mathrm{h}_{\mathrm{i}_{\text {min }}}=\left[\mathrm{H}-\left(\sum_{\mathrm{i}=1}^{\mathrm{k}} \mathrm{h}_{\mathrm{i}}+\sum_{\mathrm{i}=1}^{\mathrm{k}} \sum_{\mathrm{j}=1}^{\mathrm{m}} \mathrm{t}_{\mathrm{ij}_{\min }}\right)\right] / \mathrm{i}$,

$\Delta \mathrm{h}_{\mathrm{i}_{\max }}=\left[\left(\sum_{\mathrm{i}=1}^{\mathrm{k}+1} \mathrm{~h}_{\mathrm{i}}+\sum_{\mathrm{i}=1}^{\mathrm{k}+1} \sum_{\mathrm{j}=1}^{\mathrm{m}} \mathrm{t}_{\mathrm{ij}_{\max }}\right)-\mathrm{H}\right] / \mathrm{i}$.

Після цього вирахуємо приріст мінімального та частку зменшення максимального значень для проміжків даного типу:

$$
\begin{gathered}
\Delta \mathrm{h}_{\mathrm{ij}_{\min }}=\Delta \mathrm{h}_{\mathrm{i}_{\min }} / \mathrm{j}, \\
\Delta \mathrm{h}_{\mathrm{ij}_{\max }}=\Delta \mathrm{h}_{\mathrm{i}_{\max }} / \mathrm{j} .
\end{gathered}
$$

Остаточно стан сформованої публікації буде характеризуватися співвідношеннями

$$
\sum_{\mathrm{r}=1}^{\mathrm{k}} \mathrm{h}_{\mathrm{r}}+\sum_{\mathrm{i}=1}^{\mathrm{n}} \sum_{\mathrm{j}=1}^{\mathrm{m}}\left(\mathrm{t}_{\mathrm{ij}_{\min }}+\Delta \mathrm{h}_{\mathrm{ij}_{\min }}\right)=\mathrm{H}
$$

для мінімальних значень проміжків та

$$
\sum_{\mathrm{r}=1}^{\mathrm{k}+1} \mathrm{~h}_{\mathrm{r}}+\sum_{\mathrm{i}=1}^{\mathrm{n}} \sum_{\mathrm{j}=1}^{\mathrm{m}}\left(\mathrm{t}_{\mathrm{i} \mathrm{j}_{\max }}+\Delta \mathrm{h}_{\mathrm{ij} \max }\right)=\mathrm{H}
$$

для їх максимальних значень, що свідчить про формальне завершення процесу верстання згідно заданого алгоритму, вертикальних розмірів блоків і проміжків між ними.
Перед накопиченням чергового блоку перевіряється наявність в ньому посилання на інші блоки (наприклад, плашку, чи ілюстрацію), пов'язані з ним відповідно до змісту тексту. У цьому випадку лінійний алгоритм формування публікації розгалужується для підготування та заверстування блоку, на який $є$ посилання в основному тексті.

Таким чином, введення зони форматування в процес накопичення вертикального формату публікації та розроблення на цій основі оригінального алгоритму верстання дозволяє максимально автоматизувати процес верстання блоків полоси газети, насичених елементами складності. Відповідно скорочується час підготовки видання і тривалість спілкування оператора-верстальника 3 видавничою системою.

\section{Спосіб автоматичної вигонки} рядків тексту

Спосіб використовує алгоритм прямого набору з попереднім розрахунком нового проміжку між словами для усього абзацу у випадку його повторного формування. Цей спосіб є корисним для тексту у якому відсутній вертикальний пробільний матеріал (змінні відбивки, спуски), використання яких також дає можливість здійснювати вигонку тексту. Як наслідок, спрощується алгоритм, 3'являється можливість вибору абзацу, який оптимальний для вигонки тексту, пропуски між словами після вигонки тексту змінюються рівномірно по усьому абзаці [4]. 
Зобразимо абзац схематично (рис. 2) і на його прикладі покажемо суть пропонованого способу. Підготовка вихідних даних для вигонки здійснюється для «прямого» набору, де необхідно у кожному абзаці порахувати і запам'ятати (програмно) кількість пропусків між словами n i довжину кінцевої стрічки $\mathrm{L}_{\mathrm{k}}$.

Кінцевий рядок абзацу згідно 3 вимогами технологічних інструкцій повинен задовольняти наступні умови:

$1,5 A \leq L_{k} \leq F-K$ або $L=F$, де - А абзацний відступ; $\mathrm{K}$ - величина, рівна основному кеглю набору. Другий випадок зустрічається рідко, тому дослідимо рядки, що відповідають першій нерівності.

Нехай абзац сформований i проміжок між словами у ньому рівний д. . Границя його можливого збільшення рівна $\delta_{\max }-\delta_{r}$. У абзаці з n пропусками між словами отримаємо «резерв», рівний $\mathrm{n}\left(\delta_{\max }-\delta_{r}\right)$ знаків. Для вигонки мінімум одного рядка необхідно забезпечити виконання умови

$$
\mathrm{n}\left(\delta_{\max }-\delta_{\mathrm{r}}\right) \geq \mathrm{L}_{\mathrm{v}}+1,5 \mathrm{~A},
$$

3 (12) випливає, що для вигонки N рядків з абзацу потрібно щоб

$$
\begin{gathered}
\mathrm{n}\left(\delta_{\max }-\delta_{\mathrm{r}}\right) \geq \mathrm{F}(\mathrm{N}-1)+\mathrm{L}_{\mathrm{v}}+ \\
+1,5 \mathrm{~A} .
\end{gathered}
$$

Якщо нерівність (13) виконується, тоді приріст $\mathrm{R}_{\mathrm{n}}$ для кожного проміжку між словами в абзаці можна вирахувати за формулою

$$
\mathrm{R}_{\mathrm{n}}=\frac{1}{\mathrm{n}}\left[\mathrm{F}(\mathrm{N}-1)+\mathrm{L}_{v}+1,5 \mathrm{~A}\right] . .(14
$$

Далі здійснюється переформатування абзацу зі зміненим проміжком між словами за звичним алгоритмом «прямого» форматування. За проміжок між словами приймається $\delta_{v}=\delta_{r}+R_{n}$. При $N=1$ приріст проміжку для вигонки одного рядка буде

$$
\mathrm{R}_{1}=\frac{1}{\mathrm{n}}\left(\mathrm{L}_{\mathrm{n}}+1,5 \mathrm{~A}\right) \text {. }
$$

Для вигонки $N$ рядків газетної публікації в кожному абзаці перевіряється виконання умови (13). Далі, для усіх абзаців які задовольняють умову (13), розде $L_{v}=F-L_{k}$.

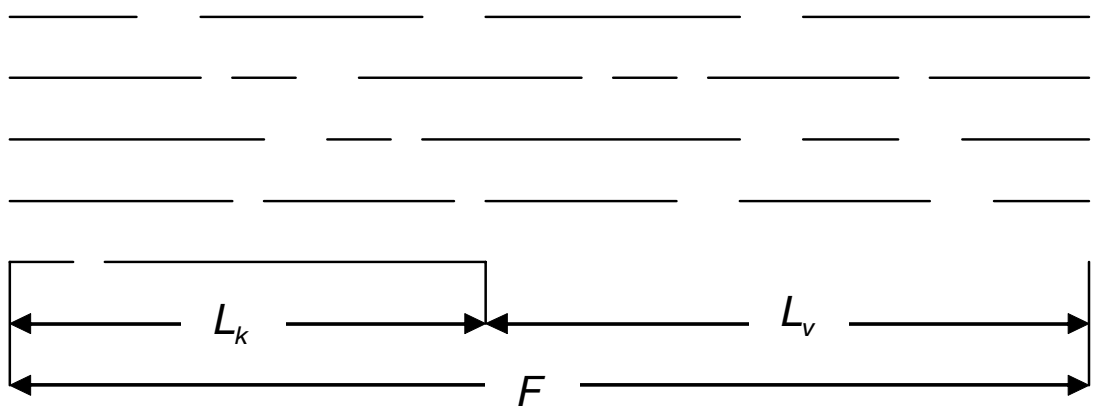

Рис. 2. Схематичне зображення абзацу для вигонки тексту 


\title{
ТЕХНОЛОГІЧНІ ПРОЦЕСИ
}

раховується приріст проміжку між словами за формулою (14). Вигонка необхідної кількості рядків виконується у тому абзаці, для якого приріст проміжку між словами мінімальний. Якщо в публікації відсутній абзац, для якого можна вигнати $\mathrm{N}$ рядків, пропонується визначити для вигонки сукупність абзаців, у яких розрахункові значення $R_{n}$ близькі між собою.

\section{Висновки}

Таким чином, у результаті дослідження розроблено математичну модель привідної верстки матеріалів газетної полоси, яка забезпечує приведення вмісту публікації до заданого розміру з дотриманням технологічних норм. Модель може стати основою алгоритму та імітаційної моделі автоматизованого макетування полос газетних видань.

1. Гавенко С. Ф. Технологія газетно-журнального виробництва. Ч. 1. Технологія газетного виробництва: навч. посіб. / С. Ф. Гавенко, 3. М. Сельменська, Л. Й. Кулік, І. М. Назар. - Львів : УАД, 2009. - 304 с. 2. Галкин С. И. Техника и технология СМИ. Художественное конструирование газеты и журнала / С. И. Галкин. - М. : Аспенд-Пресс, 2003. 232 с. 3. Дурняк Б. В. Системний аналіз та оптимізація книжкових видань: Монографія / Б. В. Дурняк, І. В. Піх, В. М. Сеньківський. - Львів : Українська академія друкарства, 2006. -197 с. 4. Сеньковский В. Н. Автоматизация фотонаборных процессов / В. Н. Сеньковский - Львов : Вища шк. Издательство при Львов. ун-те. 1987. - 140 с. 5. Галузевий стандарт України (ГСТУ 29.3-2000). Газети. Поліграфічне виконання [Текст]: Загальні технічні вимоги. К., 2000.

\author{
Рецензент - О. М. Величко, д.т.н., \\ професор, НТУУ «КП।»
}

